\title{
Diagnóstico interno del clima organizacional en una cooperativa de transportes intermunicipal de la ciudad de Palmira de conformidad al mejoramiento de su gestión administrativa
}

\author{
Martha Lucía Fuertes D. ${ }^{1}$ \\ Julio Cesar Montoya R. ${ }^{2}$
}

María Fernanda Caballero L. ${ }^{3}$

\section{RESUMEN}

El ejercicio académico que fundamenta este proyecto de grado corresponde al "Diagnóstico interno del clima organizacional en una Cooperativa de Transporte Intermunicipal de Palmira. Se realiza este proyecto, en este tipo de organizaciones, primero porque son empresas de gran dinámica de servicio, y segundo, por la complejidad interna de este tipo de compañías en cuanto a su personal que lo conforman (ejecutivos, directivos, empleados, pasantes y conductores).

Sobre la base de las consideraciones anteriores, la investigación tuvo como punto de partida, el análisis de información interna, necesaria para contextualizar la situación actual y de conformidad a la identificación de las necesidades de cambio.

La fase intermedia, corresponde a la revisión del nivel de eficacia del tipo de liderazgo y estilo de gestión gerencial de la Transportadora, la idea de este proceso era medir el trato de los directivos hacia todo su personal colaborativo y hacia sus grupos de interés (clientes, proveedores, asociados).

Por último, ante la situación detectada, se procedió a sintetizar todos los factores incidentales asociados al clima organizacional para plantear una propuesta de mejoramiento administrativo.

\footnotetext{
${ }^{1}$ Contadora Pública, Especialista en Finanzas, Maestría en Administración, docente Universidad Nacional Abierta y a Distancia - UNAD. martha.fuertes@unad.edu.co

${ }^{2}$ Administrador de Empresas, Especialista en Pedagogía para el Desarrollo del Aprendizaje Autónomo, Maestría en Administración de Empresas. Docente de la Universidad Nacional Abierta y a Distancia UNAD. julio.montoya@unad.edu.co

3 Psicóloga, Magíster en Psicología, estudiante de Doctorado en Psicología, docente Universidad Nacional Abierta y a Distancia. Grupo de investigación: Subjetividades y sujetos colectivos. maria.caballero@unad.edu.co
} 
Palabras claves: clima organizacional, motivación, trato, liderazgo, gestión

\section{Introducción}

Realmente las empresas no crecen verticalmente, sino de forma horizontal, puesto que las organizaciones se consolidan por el nivel de sinergia que logran internamente, una comunicación fluida y eficaz que se traduce en el cumplimiento de los objetivos empresariales; en tal sentido, cuando en un ambiente laboral se respira corporatividad, y los colaboradores se les nota el arraigo por la empresa, es allí donde un Gerente puede manifestar que va por buen camino, sin creer que ya el propósito se ha cumplido a cabalidad.

Cabrera, (1999), afirma que el clima laboral es la personalidad de una empresa. Asimismo menciona que el clima laboral se forma por medio de una ordenación de las características propias de la empresa. El clima es un medio donde se manifiestan las habilidades o problemas que los trabajadores tienen dentro de la empresa para aumentar o disminuir su productividad. (Maish, 2004), sostiene que evaluando el clima laboral se puede determinar las dificultades que existen en una empresa a nivel de recursos humanos. El capital humano trabaja en la empresa para facilitar o dificultar los pasos que conducirán a la productividad de los mismos, y por ende de la organización.

Diagnosticar el clima organizacional en una organización tan multidiversa en su recurso humano como una transportadora intermunicipal, suponía un desafío importante pero posible de asumir, por ello, este documento justifica su elaboración

\section{Marco Teórico}

\section{Aproximación al concepto de Clima Organizacional}

(Fernández, 1996), señalan que se considera como punto de introducción el estudio de Halpan y Croft (1963) acerca del clima en organizaciones escolares, pero anterior a éste se encuentra el de Kurt Lewin como precursor del interés en el contexto que configura lo social. Para Lewin, el comportamiento está en función de la interacción del ambiente y la persona, como ya se mencionó en el apartado de comportamiento organizacional.

Por tanto, no es de extrañar que en sus investigaciones de Lewin, acerca del comportamiento, el clima laboral aparezca como producto de la interacción entre ambiente y persona. En 1950 Cornell viene a definir el clima como el conjunto de las percepciones de las personas que integran la organización. Aunque este constructo, como tal no se elaboró hasta la década de los 60, (Fernández y Sánchez Op cit).

Los orígenes de la preocupación por el clima organizacional se sitúan en los principios de la corriente cognitiva en psicología, en el sentido de que el agotamiento de las explicaciones del comportamiento humano desde la perspectiva conductista produjo una reconciliación de la caja negra en que se había convertido a la persona. Ello 
plantea razonar acerca de la medida en que la percepción influye en la realidad misma. Esta idea comenzó a moverse por todos los campos en los que la psicología tenía su papel, entre los que se halla, por supuesto, el campo del clima laboral (Fernández, 1996).

Al respecto, (Likert, 1986), menciona que la reacción ante cualquier situación siempre está en función de la percepción que tiene ésta, lo que cuenta es la forma en que ve las cosas y no la realidad objetiva. Entonces, la preocupación por el estudio de clima laboral partió de la comprobación de que toda persona percibe de modo distinto el contexto en el que se desenvuelve, y que dicha percepción influye en el comportamiento del individuo en la organización, con todas las implicaciones que ello conlleva. Desde 1960, el estudio acerca de clima laboral se ha venido desarrollando, ofreciendo una amplia gama de definiciones del concepto. Así pues tenemos a diversos autores que han definido este campo, citados por (Furnham, 2001).

(Forehand G.A., 1964), definen al clima laboral "como el conjunto de características que describen a una organización y que la distinguen de otras organizaciones, estas características son relativamente perdurables a lo largo del tiempo e influyen en el comportamiento de las personas en la organización".

(Schneider, 1985), define el clima organizacional como un conjunto de "Percepciones o interpretaciones de significado que ayudan a la gente a encontrarle sentido al mundo y saber cómo comportarse".

(Weinert, 1987), define este concepto como "la descripción del conjunto de estímulos que un individuo percibe en la organización, los cuales configuran su contexto de trabajo".

Por otro lado, la postura operacionalista o "fenomenológica" considera "al clima laboral como una dimensión fundada a partir de las percepciones de las personas, y que tiene existencia en cuanto que hay una visión compartida, extendida en el grupo o la organización, el clima laboral está fundado en un cierto nivel de acuerdo en la forma de percibir el ambiente, si bien no es un constructo individual, sino grupal u organizacional que coincide con la visión socio cognitiva de las organizaciones". (Peiro, 1996).

Para efectos de este estudio se tomó la definición dada por (Guillén, 2000) quienes definen el clima organizacional como "la percepción de un grupo de personas que forman parte de una organización y establecen diversas interacciones en un contexto laboral"

El Clima Organizacional "consiste en la estructura organizacional y en la orientación de las personas que es un determinante de los niveles de calidad en una organización" (Kuei, Madu, \& Lin, An empirical investigation, 1997)

\section{Factores asociados al clima organizacional}


(Litwin, 1978) definen nueve dimensiones que explicarían el clima existente en una organización y que, se relacionarían con ciertas propiedades de la misma: Estructura, Responsabilidad, Recompensa, Desafío, Relaciones, Cooperación, Estándares, Conflictos e Identidad.

Para (Davis, 1997) y (Robbins, 1999), los factores a considerar, que como es sabido, se diferencian entre organizaciones, ya que cada empresa posee características únicas, serán los siguientes: Motivación, Satisfacción, Involucramiento, Actitudes, Valores, Cultura Organizacional, Estrés y Conflicto.

\section{¿Por qué diagnosticar el clima Organizacional?}

Algunos autores relacionan el clima organizacional con los siguientes factores:

- Estructura: relacionada con las reglas, trámites, procedimientos que los trabajadores deben enfrentar en el cumplimiento de su trabajo.

- Responsabilidad (empowerment): sentimiento de autonomía de los trabajadores en la toma de decisiones relacionadas con su trabajo. Medida en que la supervisión es más o menos estrecha.

- Recompensa: percepción de los trabajadores sobre la adecuación de la recompensa recibida por el trabajo bien hecho. Utilización de premios y castigos.

- Desafío: es la medida en que los trabajadores perciben su trabajo como un reto, en función del grado en que la organización acepta riesgos calculados a favor del desarrollo individual.

- Relaciones: percepción de los trabajadores de un ambiente de trabajo agradable en el que las relaciones interpersonales toman un papel preponderante.

- Cooperación: percepción de los trabajadores de la existencia de un espíritu de ayuda mutua, en donde el énfasis está puesto en el apoyo entre trabajadores y directivos.

- Estándares: percepción de los trabajadores al respecto de las normas de rendimiento fijadas por la organización.

- Conflictos: es el grado en que entre los miembros de la organización, ya sean pares o niveles superiores se acepta la diversidad de opiniones y no se teme enfrentar las discrepancias.

- Identidad: sentimiento de pertenencia a la organización y al grupo de trabajo, como un elemento valioso en el que se genera la sensación de estar compartiendo objetivos personales con los de la organización.

\section{Revisión interna de procesos por Dirección}

En virtud de medir el nivel de satisfacción de los empleados se llevó a cabo la siguiente encuesta

\section{Variable Propósito}


1. ¿Conoce la misión de la empresa donde labora?

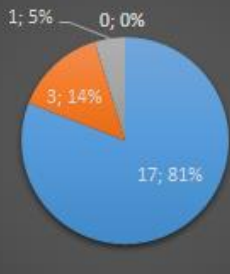

n (1) Muy de acuerdo n (2) De acuerdo (3) Neutro

2. ¿Sabe la visión de la empresa?

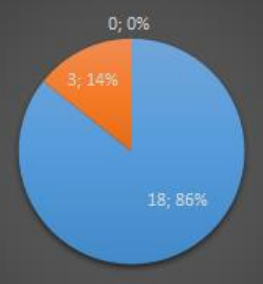

" (1) Muy de acuerdo \# (2) De acuerdo \# (3) Neutro * (4)En desacuer do $\quad$ (5) Muy en desacuerdo

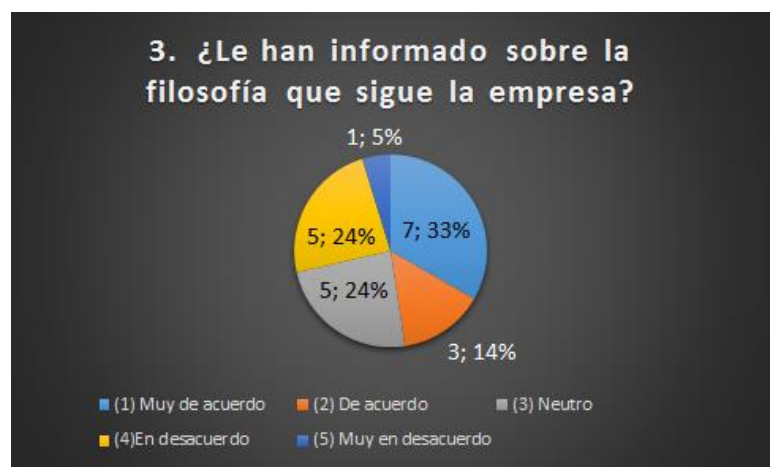

4. ¿Cree que las actividades que realiza conllevan al cumplimiento de los objetivos de la empresa?

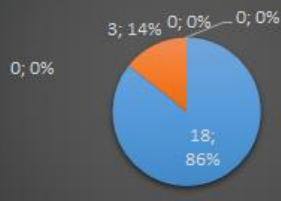


1. Las actividades que realiza son congruentes a su puesto

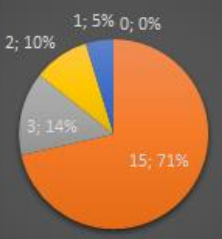

n (1) Muy de acuerdo $\quad$ (2) De acuerdo (3) Neutro

- (4)En desacuer do (15) Muy en desacuerdo

2. La división de las áreas de trabajo son adecuadas para el buen funcionamiento de la empresa

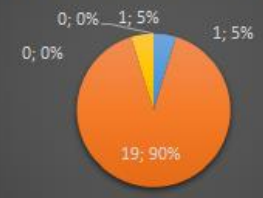

- (1) Muy de acuerdo $\quad$ (2) De acuerdo n (3) Neutro

- (4)En desacuer do (1) Muy en desacuerdo

3. Su puesto permite que desarrolle al máximo todas sus habilidades

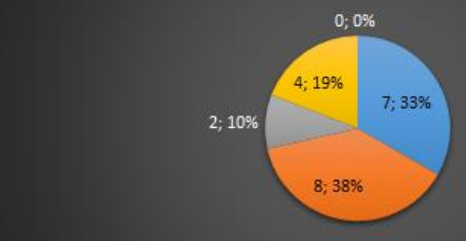

- (1) Muy de acuerdo $\quad$ (2) De acuerdo

- (3) Neutro - (4)En desacuer do

4. La empresa frecuentemente realiza rotación de puestos para eliminar el trabajo monótono

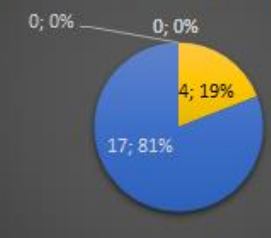




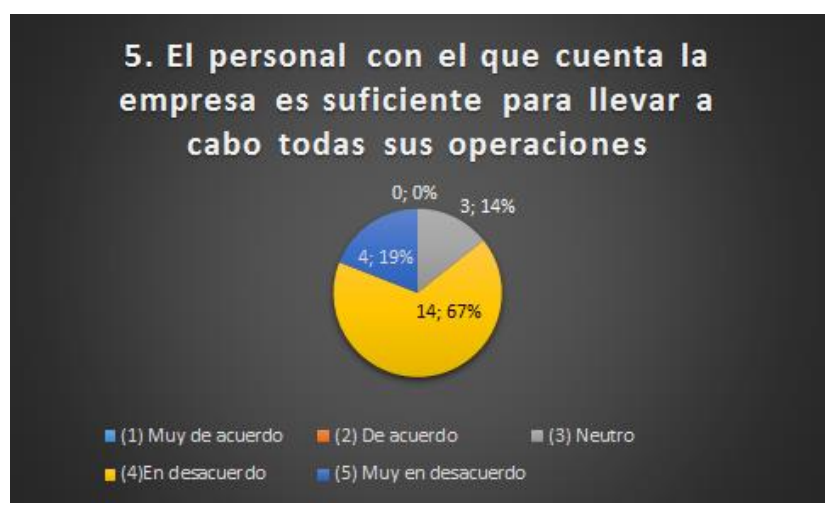

\section{Medición del impacto de la gestión gerencial}

De conformidad en comprobar el impacto de la gestión gerencial en cuanto a variables claves para el clima organizacional, respecto a sus grupos de interés, y evaluar su nivel de eficacia, se procedió a ser una entrevista grupal estructurada con cuatro (4) representantes de cada división (dirección operativa, dirección de gestión humana, dirección contable y dirección jurídica

\begin{tabular}{|c|c|c|c|c|c|}
\hline \multicolumn{2}{|c|}{ Dependencias } & \multirow{2}{*}{$\begin{array}{c}\text { Rep. Dirección } \\
\text { Operativa }\end{array}$} & \multirow{2}{*}{$\begin{array}{l}\text { Rep. Dirección } \\
\text { de Gestión } \\
\text { Humana }\end{array}$} & \multirow{2}{*}{$\begin{array}{c}\text { Rep. } \\
\text { Dirección } \\
\text { Contable }\end{array}$} & \multirow{2}{*}{$\begin{array}{l}\text { Rep. Dirección } \\
\text { Jurídica }\end{array}$} \\
\hline $\begin{array}{l}\text { Variable } \\
\text { relacionada }\end{array}$ & Pregunta & & & & \\
\hline Liderazgo & $\begin{array}{l}\text { De acuerdo a } \\
\text { los diferentes } \\
\text { tipos de } \\
\text { liderazgo que } \\
\text { se utilizan en } \\
\text { la gestión } \\
\text { administrativa } \\
\text { (liderazgo } \\
\text { coercitivo o } \\
\text { autocrático, } \\
\text { liderazgo } \\
\text { transaccional, } \\
\text { liderazgo } \\
\text { burocrático, } \\
\text { liderazgo } \\
\text { participativo y } \\
\text { liderazgo } \\
\text { carismático, } \\
\text { cual considera } \\
\text { se enmarca } \\
\text { más con lo } \\
\text { que se vive } \\
\text { internamente } \\
\text { en esta } \\
\text { organización? }\end{array}$ & $\begin{array}{l}\text {...Pues, yo diría } \\
\text { que un } \\
\text { liderazgo } \\
\text { participativo, } \\
\text { puesto que en } \\
\text { la nueva } \\
\text { administración } \\
\text { el Directora es } \\
\text { de "puertas } \\
\text { abiertas" como } \\
\text { se dice, y le } \\
\text { constantemente } \\
\text { hace reuniones, } \\
\text { llamadas } \\
\text { internas, visitas } \\
\text { las } \\
\text { dependencias a } \\
\text { indagar cosas, } \\
\text { etc. }\end{array}$ & $\begin{array}{l}\text {...Es un poco } \\
\text { complejo definir } \\
\text { qué tipo de } \\
\text { liderazgo se } \\
\text { aplica, pues mi } \\
\text { Jefe es un líder } \\
\text { carismático, } \\
\text { ejerce también } \\
\text { un liderazgo } \\
\text { participativo, } \\
\text { digamos que el } \\
\text { aplica el tipo de } \\
\text { liderazgo que } \\
\text { más le conviene } \\
\text { de acuerdo a la } \\
\text { situación. }\end{array}$ & $\begin{array}{l}\text { En la } \\
\text { administración } \\
\text { pasada, había } \\
\text { un liderazgo } \\
\text { como } \\
\text { muy...como le } \\
\text { dijera yo..sic, } \\
\text { autoritario, y } \\
\text { transaccional } \\
\text { a veces; hoy } \\
\text { con el Director } \\
\text { se maneja un } \\
\text { liderazgo más } \\
\text { democrático, } \\
\text { más } \\
\text { compartido, } \\
\text { digamos que } \\
\text { él sabe } \\
\text { escuchar... }\end{array}$ & $\begin{array}{l}\text { Respecto a su } \\
\text { pregunta, y } \\
\text { revisando la } \\
\text { forma como el } \\
\text { administra } \\
\text { (hablo del } \\
\text { Director } \\
\text { General), } \\
\text { pienso que } \\
\text { definitivamente } \\
\text { es un liderazgo } \\
\text { participativo, es } \\
\text { alguien que no } \\
\text { impone su } \\
\text { pensamiento } \\
\text { sino que lo } \\
\text { socializa, lo } \\
\text { comparte }\end{array}$ \\
\hline Nivel de Estrés & $\begin{array}{l}\text { En toda } \\
\text { empresa, se } \\
\text { manejan }\end{array}$ & $\begin{array}{l}\text { Medio: En las } \\
\text { oficinas el } \\
\text { estrés es por }\end{array}$ & $\begin{array}{l}\text { Bajo/Medio: } \\
\text { por lo regular se } \\
\text { labora en una }\end{array}$ & $\begin{array}{l}\text { Medio: no hay } \\
\text { regularidad, } \\
\text { en ocasiones }\end{array}$ & $\begin{array}{l}\text { Medio/Alto: } \\
\text { Creo que esta } \\
\text { la dependencia }\end{array}$ \\
\hline
\end{tabular}




\begin{tabular}{|c|c|}
\hline $\begin{array}{l}\text { eventos que } \\
\text { originan cierto } \\
\text { nivel de } \\
\text { estrés, en un } \\
\text { rango } \\
\text { cualitativo de } \\
\text { estrés, que } \\
\text { nivel le } \\
\text { colocaría al } \\
\text { área donde } \\
\text { labora (bajo, } \\
\text { medio, alto) }\end{array}$ & $\begin{array}{l}\text { temporadas, } \\
\text { todo depende } \\
\text { del manejo de } \\
\text { los conflictos } \\
\text { que se } \\
\text { presenten en } \\
\text { los } \\
\text { rodamientos, } \\
\text { hay días donde } \\
\text { se presenta } \\
\text { mucha cosa } \\
\text { relacionada con } \\
\text { choques, carros } \\
\text { varados, } \\
\text { quejas, etc }\end{array}$ \\
\hline
\end{tabular}

\section{Comunicación interna}

\section{Aspectos motivacionales \\ Considera en \\ forma objetiva que la Gestión Gerencial actual le apuesta al tema motivacional con sus empleados?}

Respecto a la comunicación interna entre dependencias, desde su experiencia en el día a día, que puede aportar sobre esta variable?
Pues yo diría, que sin ser excelente, es muy aceptable, pienso que al modernizar la comunicación con la tecnología, la comunicación fue más fluida ambiente

amigable, usted

lo puede ver,

creo que la

modernización

de las

instalaciones

ayudo mucho, en la sede

antigua, estábamos muy

hacinados, y

eso creaba

sobreesfuerzos, roces, estrés general sobre todo a fin de mes

\section{Entiendo por} comunicación, el nivel de interacción entre la gente, respecto a informes, datos, gestiones, si es así, la comunicación es eficiente
Sí, yo diría que sí, motiva el saber que uno puede participar en los procesos; motiva el saber que hay estabilidad laboral; motiva trabajar en instalaciones modernas, y motiva saber que hay lugar para el se ve mucha gente en las dependencias, cuando eso sucede, el clima se pone tenso, por eso digo que el nivel de estrés es medio.

Mejoró mucho
respecto a la
administración
anterior, se
dificulta un
poco cuando
hay persona
nuevo, porque
en la empresa
no se tiene
muy en
cuenta la
capacitación
para los
recién
ingresados

ingresados

Para mi si, se ve la gente contenta, animada, y eso se siente, obviamente uno de los principales motivadores sería una mejor remuneración salarial, pero al menos hay oportunidad de hacer

$\begin{array}{ll}\text { La principal } & \text { Para mi si, se } \\ \text { motivación } & \text { ve la gente } \\ \text { pienso yo, es } & \text { contenta, } \\ \text { que la gente } & \text { animada, y } \\ \text { trabajo en las } & \text { eso se siente, } \\ \text { mejores } & \text { obviamente } \\ \text { condiciones } & \text { uno de los } \\ \text { ambientales y } & \text { principales } \\ \text { laborales, en } & \text { motivadores } \\ \text { ese sentido la } & \text { sería una } \\ \text { Cooperativa se } & \text { mejor } \\ \text { ha esmerado } & \text { remuneración } \\ \text { por mejorar esta } & \text { salarial, pero } \\ \text { parte } & \text { al menos hay } \\ & \text { oportunidad } \\ & \text { de hacer }\end{array}$

La

comunicación interna en términos generales es eficiente, lo que sucede es que esta dependencia particularmente, maneja como le decía muchos asuntos delicados con abogados, usuarios, asociados que no permiten que el flujo de comunicación

sea el adecuado Mmm, pues, que le digo, si, La Gerencia es entusiasta, y se transmite este hábito en todas las dependencias, se trabaja duro, pero eso también motiva
donde más maneja, pues procesos jurídicos que entonces la torna pesada, sobre todo en los fines de mes.




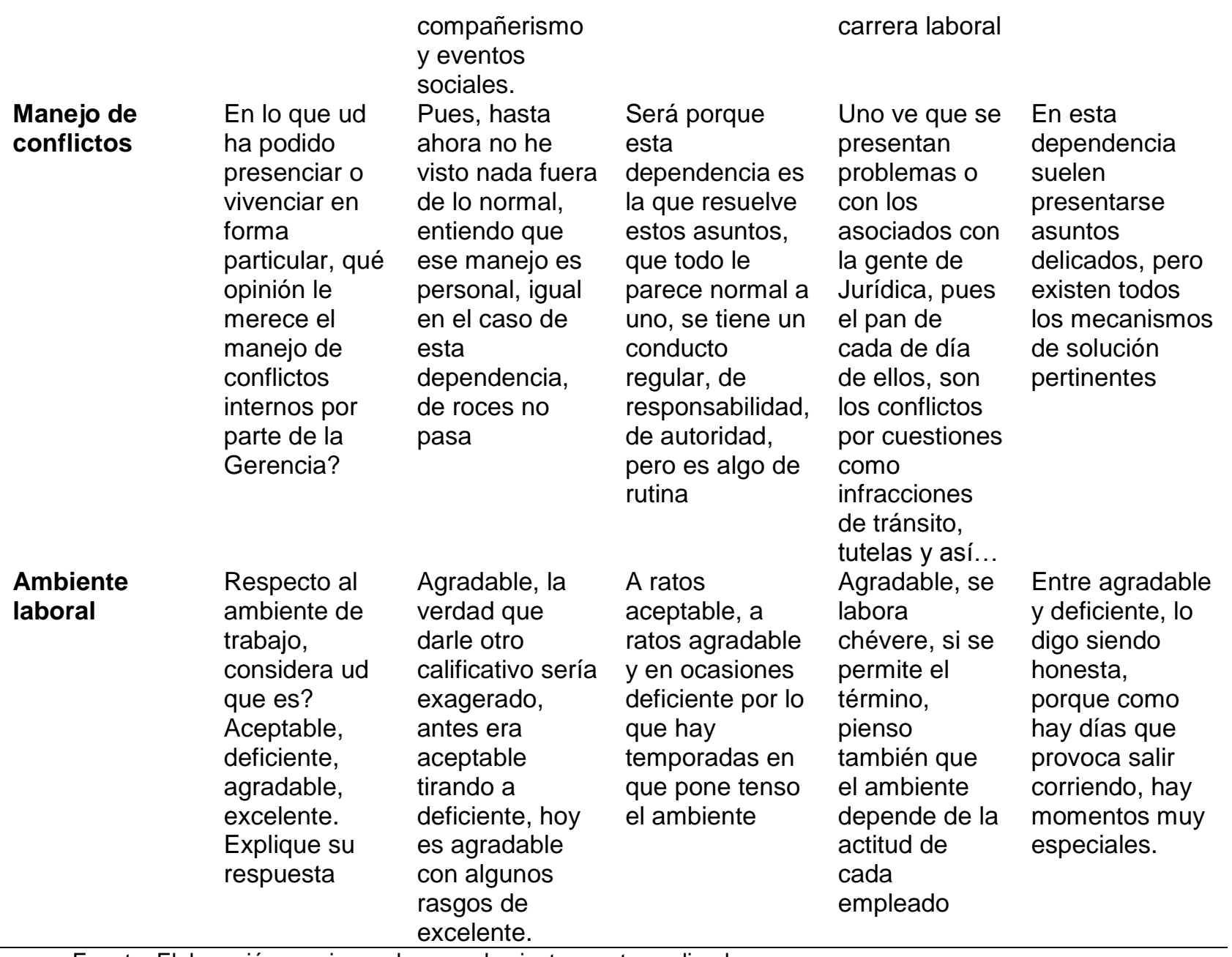

Fuente: Elaboración propia con base en los instrumentos aplicados

\section{Resultados y discusión}

Con base en el trabajo de campo realizado en el diagnóstico se identificaron las siguientes posibilidades de mejora:

Creación de oportunidades de desarrollo y crecimiento profesional al interior de la organización: en esta empresa en particular, según indagaciones previas, ya se está promocionando algunos cargos, lo que de por si constituye un precedente positivo, aunque lo ideal es que dicha gestión se pueda aplicar a otras dependencias en la medida de las posibilidades y objetivos corporativos.

Favorecer ambientes meritocráticos en los que se reconozca el potencial y el desempeño: En este aspecto se ha mejorado, según cuentan algunos empleados, en administraciones anteriores, se incurría en prácticas de nepotismo, lo que generaba un ambiente tenso y de inconformismo generalizado.

Establecer entornos de trabajo flexibles: Habría que reformular algunos procesos puntuales, pero la posibilidad está abierta teniendo en cuenta que la Gerencia es 
proclive a ideas novedosas y que agreguen valor a la empresa, y que faciliten la consecución de los objetivos corporativos.

Realizar actividades de salud y recreación para los colaboradores: Existe una programación con toda la bitácora de actividades a realizar, pero se puede optimizar, porque según se indagó, muchas de las actividades lúdico-recreativas competen solo a la práctica del futbol, al juego de sapo y al billar pool; pero pueden diversificarse para la conformidad total de los colaboradores y grupos de interés (stakeholders).

Involucrar al núcleo familiar del trabajador en actividades de la empresa: Esto se hace, pero no en todas las actividades, podría mejorarse o ampliarse el portafolio de oferta lúdico recreativa, en la navidad más reciente se hizo una Yincana que incluyo la participación de familiares, y se tuvo la mejor de las experiencias sociales.

Invertir tiempo y esfuerzos para guiar a las personas en aspectos como capacitación entrenamiento: Este es un proceso que queda pendiente, puesto que la empresa tiene otro tipo de prioridades, pero como se le manifestaba a los colaboradores internos de este proyecto, no es un asunto que deban desestimar, puesto que a futuro puede ocasionar problema de duplicidad de funciones, confusión, conducto regular alterado, etc.

Mantener canales de comunicación y ponerlos al alcance de todos: En el contexto de oficinas, los canales son óptimos, no así con los operativos, la idea y recomendación especial que se les hizo a los colaboradores de este proyecto, es que se logre "estandarizar este proceso", por el solo hecho de que unas áreas tengan y otras no, ocasiona voces de inconformismo.

Proveer sueldos y paquetes de prestaciones competitivas: Este aspecto demanda mayor complejidad, por la connotación financiera que conlleva incrementar salarios, pero la Transportadora tiene la posibilidad financiera de mejorar este rubro, entonces potencialmente es un gran estímulo, para el contexto motivacional del empleado.

\section{Conclusiones}

Con base en el objetivo uno, se observa que evidentemente existe un consenso general sobre un nivel de satisfacción conforme, existe una polarización en algunas variables, pero no son tan representativas, más bien obedecen a hechos aislados, o a posiciones muy particulares, que de todas formas no deben de desestimarse, puesto que una persona inconforme, potencialmente puede generar comentarios que redunden en conflictos a posteriori

En lo que concierne al segundo objetivo, el impacto de la Gestión Gerencial, en todas sus variables ha sido positivo, el común denominador es que la nueva administración ha llevado a cabo una buena labor, sobre todo en la apuesta de participación de los grupos de interés en la toma de decisiones, existe de todas formas unas voces de inconformismo, por parte del personal de la dependencia jurídica, pero es totalmente entendible, por el volumen de conflictos y situaciones de delicado manejo que allí se presentan, pero que no son imposibles de superar. 
En lo que atañe, al tercer objetivo, se identificaron oportunidades de mejora, con base en los hallazgos de los instrumentos utilizados en las fases uno y dos, no obstante su valor fáctico depende de la aprobación de la Dirección General (Gerencia) y de los asociados, puesto que este proceso implica cambios sustanciales por un lado (reformulación de procesos, contratar más personal, inversión en capacitación, entre otros)

\section{FUENTES DOCUMENTALES}

Davis, K. Y. (1997). Comportamiento humano en las organizaciones. México: Editorial McGraw Hill.

Fernández, M. y. (1996). Manual de prácticas de psicología. Madrid: Amarú.

Forehand G.A., G. B. (1964). Environmental Variation in studies of organizational behavior. . Chicago: Psychological Bulletin.

Furnham, A. (2001). Psicología organizacional del comportamiento del individuo en las organizaciones. México: Oxford.

Guillén, C. y. (2000). Psicología del trabajo para relaciones. Madrid: McGraw Hill.

Kuei, C., Madu, C., \& Lin, C. y. (1997). An empirical investigation. Chicago: International Jour nal of Quality Science.

Likert, R. (1986). Nuevas formas para solucionar conflictos. México: Trillas.

Litwin, G. Y. (1978). Organizational climate. New York: Simon.

Maish, E. (2004). Pautas metodológicas para la realización de estudios de clima organizacional. Gestión del tercer milenio.

Peiro, J. y. (1996). Tratado de psicología del trabajo. La actividad laboral en su contexto. Madrid: Amarú.

Robbins, S. (1999). Comportamiento organizacional. México: Prentice Hall.

Schneider, B. (1985). Organizational behavior. New York: Annual Review Psychology, $36,573-611$.

Weinert, B. (1987). Manual de Psicología de la Organización. Barcelona: Herder. 